\title{
PRODUZINDO CURRÍCULOS E PROFESSORES DE CIÊNCIAS NA EJA: ENTRE NORMALIZAÇÕES E DESLOCAMENTOS
}

\author{
Juliana Marsico ${ }^{(*)}$ \\ Marcia Serra Ferreira ${ }^{(* *)}$
}

\section{INTRODUÇÃO}

Nesse texto, investigamos os discursos que regulam os processos de subjetivação de professores em formação inicial para a atuação na Educação de Jovens e Adultos (EJA). ${ }^{1}$ Interessanos compreender os enunciados produzidos em diferentes contextos discursivos de produção de conhecimentos que normatizam o que podemos pensar sobre a modalidade e seus sujeitos professores e estudantes -, em processos que incluem e, simultaneamente, excluem as pessoas jovens e adultas. Buscamos, assim, entender as regras que constituem os sistemas de raciocínio que produzem regimes de verdade (FOUCAULT, 2003, 2014a, 2014b) em meio aos quais viemos significando currículos, professores e estudantes considerados 'apropriados' para a EJA.

Para realizar essa tarefa, investigamos documentos/monumentos (FOUCAULT, 2014a) produzidos em diferentes contextos discursivos: (i) documentos oficiais que instituíram as Diretrizes Curriculares Nacionais para a Educação de Jovens e Adultos no Brasil - Resolução CNE/CEB n 01/2000 (BRASIL, 2000a) e Parecer CNE/CEB n 11/2000 (BRASIL, 2000b) -; (ii) documentos elaborados por professores em formação no curso de Licenciatura em Ciências Biológicas da UFRJ e nomeados de diários da prática pedagógica, com reflexões acerca das experiências vividas na Prática de Ensino e, em especial, nas aulas que os licenciandos acompanharam em turmas da EJA. Na análise, consideramos que as políticas não são definidas por sujeitos racionais e autônomos que detém o poder sobre o que podemos pensar e como podemos agir em relação à educação. Diferentemente,elas são produzidas em meio a um ciclo contínuo, tal

\footnotetext{
${ }^{(*)}$ Professora da Faculdade de Educação da Universidade Federal do Rio de Janeiro, integra o corpo de pesquisadores do 'Grupo de Estudos em História do Currículo', no âmbito do NEC/UFRJ.

${ }^{(* *)}$ Professora da Faculdade de Educação e do Programa de Pós-Graduação em Educação da Universidade Federal do Rio de Janeiro, coordena o 'Grupo de Estudos em História do Currículo', no âmbito do NEC/UFRJ. É Bolsista de Produtividade 2 do CNPq e Cientista do Estado (CNE/Faperj).

${ }^{1}$ Ele é parte da pesquisa de doutorado da primeira autora (MARSICO, 2018), que se desenvolveu em articulação com os projetos de pesquisa 'Reformas em curso na formação de professores em Ciências Biológicas: significando a inovação curricular no tempo presente' e 'História do Currículo e das Disciplinas: desenvolvimento e uso de uma abordagem discursiva para investigações no ensino e na formação de professores', com financiamentos do $\mathrm{CNPq}$, Capes e CNE/Faperj.
} 
como proposto por Stephen Ball \& Richard Bowe (1992), com a circulação e a transformação de textos e sujeitos. Nessa abordagem, Ball \& Bowe (1992) usam o termo encenar para se referir aos processos de tradução que sofrem os textos políticos quando transformados em práticas. Para o autor, ao serem encenados, os textos legais estão sujeitos a interpretações e recriações em espaços como escolas e universidades, abrindo espaço para as subversões. Em tal perspectiva, mobilizamos um entendimento sobre o poder como uma ação sobre ações possíveis (FOUCAULT, 1995) e que se distribui, de forma assimétrica, na rede de relações nas quais se inserem a produção e a encenação das políticas, aqui entendidas como discurso.

Investigamos os referidos documentos/monumentos curriculares, portanto, não como políticas que controlam, desde um centro de poder, as ações na modalidade, mas como textos que regulam, junto a outros discursos, o que significa uma educação de qualidade para as pessoas jovens e adultas. Isto significa entender que a EJA é reinterpretada e recriada nas distintas instituições de ensino, o que pode dar visibilidade a processos de resistência e/ou subversão. Assumir a hipótese de que as políticas estão sujeitas à recontextualização significa, em última instância, questionar qualquer pretensão que se tenha de controlar os sentidos dos textos (BALL; BOWE, 1992); afinal, a ação de sujeitos diferentemente posicionados nas políticas desencadeia a formação de estratégias curriculares híbridas, que constituem sítios potenciais de resistência, de intervenção e de tradução (HALL, 1997).

Julgamos importante destacar que não partimos da premissa de que existe uma formação específica para que professores possam atuar na EJA. De igual modo, não intencionamos compreender como seria uma melhor formação docente para a atuação na modalidade. Diferentemente, partimos de uma experiência formativa específica - o estágio curricular do curso de Licenciatura em Ciências Biológicas da Universidade Federal do Rio de Janeiro (UFRJ) -, buscando compreender como esta é atravessada por enunciados que produzem sentidos de (e para a) EJA, assim como para os seus sujeitos. Isso significa que não pretendemos, portanto, formular novos discursos sobre a EJA - ainda que isso também possa estar acontecendo ${ }^{2}$-, mas destacar as fronteiras que circunscrevem os já-ditos e, nesse sentido, contribuir para a emergência de outras possibilidades de se pensar tanto a modalidade quanto a própria formação de professores. Afinal,

\footnotetext{
${ }^{2}$ Inseridas em uma perspectiva teórica que focaliza os discursos que constroem sistemas de raciocínio que regulam o que vem sendo significado como o currículo e a formação docente da (e para a) EJA, esta pesquisa produz, igualmente, determinados enunciados que significam tais noções. Consideramos, portanto, que, ao ocupar a posição de sujeito de pesquisadoras em Educação e, mais especificamente, em História do Currículo, o que aqui é dito também produz verdades sobre as quais são significados o currículo e a formação docente no âmbito desta modalidade.
} 
muitos dos processos de formação inicial no país incluem e são impactados por experiências nessa modalidade da educação básica.

É em meio a tal movimento que consideramos potente a noção de experiência. No diálogo com Michel Foucault (2010) e Jorge Larossa (2009), mobilizamos essa noção como todo percurso por onde passamos e saímos transformados, como uma experiência sensível, uma vez que supõe uma relação entre o sujeito e um acontecimento que lhe é exterior/estranho. Nessa relação, o sujeito é um território dessa experiência, uma superfície de sensibilidade em que algo passa e que o transforma, deixando marcas e produzindo, portanto, uma subjetividade. Nesse estudo, portanto, o foco é colocado na maneira como a experiência de estágio na EJA passa pelos professores em formação e os transforma, participando do processo de subjetivação docente desses sujeitos.

\section{PRODUZINDO OS SUJEITOS DA EJA NA FORMAÇÃO INICIAL DE PROFESSORES}

Como já explicitado, mobilizamos a noção de experiência para refletir acerca das políticas elaboradas nos diferentes contextos - isto é, tanto na formulação dos textos oficiais quanto na produção escrita sobre o estágio curricular - como acontecimentos que possibilitam irromper subjetividades docentes. O próprio ato de escrever tanto os documentos legais da (e para a) EJA quanto os diários da prática pedagógica pode ser visto como parte das experiências que subjetivam e transformam os sujeitos. Apoiadas em Michel Foucault (2010), analisamos tais documentos/monumentos como escritos desta trajetória específica, na qual os diários da prática pedagógica não apenas registram as vivências dos licenciandos em seus estágios. Diferentemente, eles são atravessados e atravessam os textos legais, em movimentos que significam ambas as experiências. Entendemos, portanto, que escrever é uma maneira de experimentar-se, um movimento que muda quem escreve, em uma constante experiência de deslocamento e de transformação (FOUCAULT, 2010). Afinal, para Foucault (1992, p.151, grifo original), "escrever é, pois, mostrar-se, dar-se a ver, fazer aparecer o rosto próprio junto ao outro". Entendendo a experiência da EJA como um acontecimento que rompe a continuidade do tempo vivido pelos professores em formação - uma vez que, em suas trajetórias escolares, não haviam experimentado essa modalidade -, buscamos compreendê-la como uma experiência que regula o processo de formação docente desses sujeitos.

$\mathrm{Na}$ análise aqui empreendida, estivemos interessadas não em quem diz, mas sim no que é dito. Mobilizamos, assim, aquilo que Foucault (2014b) define como a positividade dos discursos, buscando entendê-los como "produtivos na constituição de processos de regulação social que hegemonizam sentidos de escola, ensino, professor, aluno e conhecimento" (FERREIRA, 2013, 
p.85). Nossa meta foi, então, a de produzir uma "descrição dos acontecimentos discursivos como horizonte para a busca das unidades que aí se formam” (FOUCAULT, 2014a, p. 32-33, grifos originais), com foco nas relações que produzem as regularidades discursivas sobre a EJA e subjetivam os professores em formação. Ao produzirmos uma história sobre a irrupção de subjetividades docentes, não estivemos em busca de um jogo de causas e efeitos, mas sim em “estabelecer as séries diversas, entrecruzadas, divergentes muitas vezes não autônomas, que permitem circunscrever o 'lugar' do acontecimento, as margens de sua contingência, as condições de sua aparição" (FOUCAULT, 2014a, p. 53).

Procuramos, portanto, compreender como os discursos produzem sistemas de raciocínio (POPKEWITZ, 2014) e fabricam (HACKING, 2007; POPKEWITZ, 2001 e 2008) tipos específicos de sujeitos, sejam eles estudantes jovens e adultos, sejam professores que atuam na modalidade. Concordando com Popkewitz (2001) quando este autor destaca que o próprio raciocínio representa um problema a ser investigado - uma vez que porta normas e valores que, historicamente, funcionam para confinar os alunos -, percebemos que a formação inicial aqui investigada não ensina aos futuros professores de Ciências e Biologia apenas o conhecimento per se, mas ideias que disciplinam escolhas e regulam ações. Assim, em meio a um sistema de raciocínio que normaliza o ensino regular, seus professores e estudantes, criando padrões por meio dos quais definimos o outro, vimos percebendo o quanto a EJA, assim como os seus sujeitos, vêm sendo percebidos, historicamente, como fora da norma.

Nessa direção, no diálogo com Thomas Popkewitz, percebemos, nas superfícies textuais investigadas, a caracterização do estudante jovem e adulto sendo elaborada em meio a um par binário que forma "um contínuo de valores em que um lado das distinções é privilegiado, à medida que o conjunto cria o que é bom e normal” (POPKEWITZ, 2001, p. 48, grifos originais). Ainda para o autor, "os binários recompõem as normas sociais em um contínuo de valores de modo a classificar as ações do ensino", de modo que "as diferenças são produzidas como normas universalizadas sobre o que deve ser o mesmo" para todos os estudantes, mas em que os estudantes jovens e adultos diferem (POPKEWITZ, 2001, p. 49). É com tal perspectiva que, em nossa análise, evidenciamos a constituição de um par binário formado pelo aluno regular versus o aluno da EJA, no qual o estudante jovem e adulto vai sendo posicionado como excluído do processo educativo escolar. Tal posição, no entanto, que é marcada por uma trajetória escolar não regular, pela idade adulta e por experiência de vida adulta fora da escola, é também positivada em discursos que classificam tais alunos como mais firmemente interessados em concluir o percurso escolar, além de portarem conhecimentos da vida prática que devem e podem ser usados para significar tal percurso. 
Além disso, ao analisar formações discursivas que produzem uma estrutura de ideias sobre a modalidade, mobilizamos também o entendimento de Popkewitz (2011) de que a escolarização acarreta um duplo gesto: a inscrição de teses cosmopolitas sobre o aluno como futuro cidadão e os processos de abjeção, com o banimento daqueles alunos que constituem temores ao futuro. O autor defende que, embora o uso do termo cosmopolitismo não seja comum nas reformas escolares, seus pressupostos circulam nas mesmas, enraizadas na pedagogia, no currículo e na formação de professores. Estamos, nesse sentido, de acordo com Popkewitz (2008, 2009 e 2011) quando ele afirma ser interessante investigar o fato de que esse cidadão é fabricado por tais políticas e pelas ciências da educação. Para o autor, é esse o ponto em que a escolarização e as ciências pedagógicas se tornam cruciais, uma vez que a mesma unidade que produz o cidadão que "aprende" também é a que gera diferença, em um movimento que "traz à superfície a importância e os limites de um número de qualidades e características significativas da vida moderna que nos impõe quem somos, quem devemos ser e quem não está apto a ser como nós", seja como estudantes, seja como professores (POPKEWITZ, 2009, p. 12, grifos originais, tradução livre).

No que se refere aos estudantes, vimos percebendo o quanto essa distinção diz respeito ao fato de a modalidade abrigar diferentes faixas etárias, com trajetórias de vida que se diferenciam daquelas que costumamos considerar como sendo normais para alunos do ensino fundamental e médio na escola. Esta distinção se refere, portanto, aos sistemas de raciocínio por meio do qual pensamos a educação escolar e que nos informam que não apenas a escola é, normalmente, o lugar onde as crianças aprendem, mas é, simultaneamente, a vivência que nos prepara para a vida do trabalho (POPKEWITZ, 2001, 2008 e 2011). É em meio a tais sistemas que os estudantes da EJA, jovens e adultos em idade superior à que é considerada regular para a escolarização básica e, em sua maioria, trabalhadores, são enunciados como estudantes que necessitam de outro currículo. Tal currículo, nos textos legais, deve considerar que "as situações, os perfis dos estudantes, as faixas etárias e se pautará pelos princípios de equidade, diferença e proporcionalidade na apropriação e contextualização das diretrizes curriculares nacionais e na proposição de um modelo pedagógico" (Parecer CNE/CEB n 01/2000, p. 1). Afinal,

(...) a EJA é um modo de ser do ensino fundamental e do ensino médio, com seus homólogos voltados para crianças e adolescentes na idade adequada, [sendo] chaves de abertura para o mundo contemporâneo em seus desafios e exigências mais urgentes e um dos meios de reconhecimento de si como sujeito e do outro como igual. (Parecer CNE/CEB n ${ }^{\circ}$ 01/2000, p.67, grifos nossos).

Tal distinção, como já explicitado, também se refere ao fato de a EJA atender a estudantes relacionados ao mundo do trabalho, sendo percebidos como "via de regra mais pobres e com vida 
escolar mais acidentada" (Parecer CNE/CEB n 11/2000, p. 9). Compreendemos, portanto, nos discursos que circulam sobre (e para) a modalidade, a produção de um certo tipo de sujeito quando se referem aos estudantes jovens e adultos, que são classificados como "estudantes que aspiram a trabalhar, trabalhadores que precisam estudar" (Parecer CNE/CEB n ${ }^{\circ} 11 / 2000$, p. 9). Nesse contexto:

O importante a se considerar é que os alunos da EJA são diferentes dos alunos presentes nos anos adequados à faixa etária. São jovens e adultos, muitos deles trabalhadores, maduros, com larga experiência profissional ou com expectativa de (re)inserção no mercado de trabalho e com um olhar diferenciado sobre as coisas da existência [...]. Para eles, foi a ausência de uma escola ou a evasão da mesma que os dirigiu para um retorno nem sempre tardio à busca do direito ao saber. Outros são jovens provindos de estratos privilegiados e que, mesmo tendo condições financeiras, não lograram sucesso nos estudos, em geral por razões de caráter sociocultural (Parecer CNE/CEB n 11/2000, p.34-35).

Além disso, como uma modalidade específica da educação básica, a EJA apresenta diferenças em relação à organização dos tempos e espaços que, tradicionalmente, vimos considerando normal na cultura escolar. É em meio a tais diferenças que vem sendo projetado um outro professor para atuar na modalidade, sendo discursivamente produzida a necessidade de uma formação especificamente voltada para o ensino de jovens e adultos, "trabalhadores ou não, com marcadas experiências vitais que não podem ser ignoradas" (Parecer CNE/CEB n 11/2000, p. 58).Tais especificidades funcionam como uma regra, uma regularidade discursiva que regula os significados do ensino e da formação de professores para a EJA, em um movimento que afirma a complexidade da modalidade ao destacar que:

(...) o preparo de um docente voltado para a EJA deve incluir, além das exigências formativas para todo e qualquer professor, aquelas relativas à complexidade diferencial desta modalidade de ensino. [...] Jamais um professor aligeirado ou motivado apenas pela boa vontade ou por um voluntariado idealista e sim um docente que se nutra do geral e também das especificidades que a habilitação como formação sistemática requer (Parecer CNE/CEB n ${ }^{\circ}$ 11/2000, p. 53-56).

\section{ENTRE NORMALIZAÇÕES E DESLOCAMENTOS: EFEITOS DE INCLUSÃO/EXCLUSÃ O}

Como já explicitado, vimos percebendo a fabricação de uma certa formação de professores, assim como de um certo tipo de professor, para atuar nessa modalidade da educação básica, produzindo efeitos de poder que regulam a produção das subjetividades docentes. É nesse 
movimento que vai sendo produzido um outro par binário (POPKEWITZ, 2001), posicionando o professor da EJA como o outro da relação entre docentes da educação básica, com a valorização de características que, em outros contextos de ensino, não seriam necessariamente atribuídas ao bom professor. Neste movimento, este outro professor deve flexibilizar horários e prazos, além de produzir práticas pedagógicas adequadas ao aprendizado desse estudante fora da norma, "uma vez que muitos alunos trabalham e tem outras ocupações em suas vidas que não a escola" (DPP 12/2015). Sobre isso, destacamos:

O professor regente de Ciências que acompanhamos durante o estágio [...] desenvolve práticas pedagógicas diferenciadas em relação ao sistema educacional vigente. Ele busca integrar conhecimentos do cotidiano com conhecimentos escolares e científicos, sem deixar de considerar os conhecimentos prévios do seu alunado. Estes, muitas vezes, podem ser usados como exemplos de conteúdos em Ciências que estão relacionados com a sociedade (DPP 7/2015).

A flexibilização curricular e a integração de conhecimentos cotidianos no currículo escolar são enunciadas como aspectos diferenciais da educação na referida modalidade de ensino. Ambos os aspectos são frequentemente associados à postura de um professor comprometido com a educação daqueles que não tiveram oportunidades de estudar em idade apropriada e o fazem simultaneamente ao cotidiano de trabalho. Em uma aula na modalidade relacionada ao tema “propriedades da água $\left(\mathrm{H}_{2} \mathrm{O}\right)$ ” (DPP 13/2015), por exemplo, os licenciandos destacam o quanto:

O professor, sempre que possível, tenta relacionar o assunto estudado com os acontecimentos globais. É muito importante fazer esses links, pois os alunos conseguem assimilar melhor o conteúdo. Neste caso, que estão estudando as propriedades da água, comentamos também o cenário atual de escassez e também a importância para a saúde (DPP 13/2015).

Outro exemplo de como aspectos do ensino de Ciências se relacionam, na EJA, com questões referentes à flexibilização curricular e à integração de conhecimentos cotidianos refere-se a uma atividade que, utilizando reportagens de jornais em circulação, pôde mesclar conhecimentos disciplinares com atividades de letramento. Ao encontrarem, em uma sala de aula correspondente às séries finais do ensino fundamental, estudantes com limitações no que diz respeito à leitura e escrita, os licenciandos, inicialmente, se assustaram e se perguntaram como seria possível ensinar Ciências em tais turmas. Partindo desse questionamento, estes professores em formação se deslocaram e passaram a buscar maneiras de trabalhar leitura e escrita enquanto ministravam a disciplina escolar Ciências. Assim, em uma das escolas campo de estágio, estes passaram a realizar atividades nas quais pediam aos alunos que trouxessem recortes de jornais com reportagens 
relativas a assuntos que julgassem ser possível discutir nas aulas de Ciências. Dividindo os estudantes em grupo, os licenciandos propunham a leitura das reportagens, a discussão dos assuntos e a produção de outros textos pelos próprios alunos. Tais produções, após apresentação para a turma e nova discussão, serviram de material para a elaboração, ao fim do trimestre, de um 'Jornal Científico'. Tais atividades passaram a ocorrer nos primeiros trinta minutos de cada aula, sob a supervisão do professor regente, subvertendo o modo como certos licenciandos significavam seus estudantes, o currículo e o próprio ofício docente em turmas da EJA:

Hoje foi o primeiro dia de atividade com a turma 152. A experiência foi muito legal e reveladora. Achávamos que seria bem difícil para eles entenderem as reportagens [...]. Na verdade, foi o contrário [...] [e] a atividade de hoje mostrou que eles não estão em um nível tão 'basal' como estávamos imaginando. [...] eles releram as notícias, se organizaram para apresentar para a turma (DPP 9/2016).

Percebemos, portanto, na análise realizada, a necessidade de fabricar professores que produzam um outro currículo para a modalidade. Tal currículo tem sido enunciado em meio a uma estrutura de ideias que distingue o aluno da EJA do estudante considerado normal, em um movimento que posiciona o currículo do ensino regular como referência normativa a partir do qual são estabelecidas regras baseadas nas competências e necessidades deste outro estudante (POPKEWITZ, 2001). Desta forma, em alguns enunciados, o que parece estar em jogo no movimento de redução e flexibilização curricular é a produção de um estudante carente, seja de tempo para estudar, seja de base para acompanhar as aulas que, em uma situação normal, seriam ministradas no âmbito do ensino regular. Não se trata aqui de focalizar a quantidade e/ou a qualidade de conteúdos que são mobilizados em cada modalidade, mas de perceber o raciocínio que produz essa diferença e que regula as ações do professor.

Em outros enunciados, no entanto, a questão de flexibilidade parece dizer respeito à seleção de conteúdos, estando relacionada ao fato de esses estudantes apresentarem experiências que são consideradas como enriquecedoras do processo educativo. É nesse sentido que o currículo da EJA deve incluir conteúdos que sejam relacionados com as experiências de vida desses estudantes. Afinal,

A flexibilidade curricular deve significar um momento de aproveitamento das experiências diversas que estes alunos trazem consigo como, por exemplo, os modos pelos quais eles trabalham seus tempos e seu cotidiano. A flexibilidade poderá atender a esta tipificação do tempo mediante [...] uma sintonia com temas da vida cotidiana dos alunos, a fim de que possam se tornar elementos geradores de um currículo pertinente (Parecer CNE/CEB n ${ }^{\circ}$ 11/2000, p.61). 
Percebemos, nesse mesmo movimento, que as características que desqualificam esses estudantes são também positivadas quando "normas responsáveis pelas diferenças são também reimaginadas como atributos positivos", funcionando como "suposta rota de salvação" (POPKEWITZ, 2001, p. 50, grifos originais) dos estudantes da EJA. É o que ocorre quando, ao valorizar a trajetória de vida do estudante jovem e adulto que não esteve na escola em idade adequada, licenciandos e professores positivam algo que é tido como ausência. Afinal, o encontro entre essa experiência da vida adulta e a educação básica só existe pelo fato de tal estudante não ter tido a experiência de escolarização em idade considerada adequada. Nesse movimento, entretanto, ainda que as experiências dos estudantes jovens e adultos sejam mobilizadas com pretensões de inclusão, os currículos mantêm a diferença em relação ao conhecimento escolar, uma vez que é este que é classificado como norma no que se refere à trajetória de escolarização, sendo considerado, portanto, o conhecimento que é direto de todos. Em diálogo com Popkewitz (2011), entendemos que tais iniciativas, apoiadas no compromisso com uma sociedade justa e equitativa, promovem, simultaneamente, processos de abjeção e exclusão. Afinal, tal movimento é parte de um sistema de raciocínio que, ao promover inclusão, também normatiza e confina os sujeitos da EJA, estudantes e professores, em um espaço que incorpora a responsabilidade moral de redenção dos primeiros por parte da ação dos segundos. Em tal perspectiva, isso significa que, ao nos referirmos aos estudantes jovens e adultos como cidadãos que necessitam de estratégias de produção de igualdade, os localizamos em espaços intermediários entre a inclusão e a exclusão.

Nesses espaços intermediários, é muito comumente enunciada a ideia de que um bom professor de Ciências e Biologia na EJA não é apenas aquele que valoriza os saberes do cotidiano desse estudante jovem e adulto, mas também o que traz para sua aula a preocupação com atividades diferenciadas e integradas. Nos diários da prática pedagógica, as características de uma boa aula para a modalidade aparecem relacionadas à referida preocupação e parecem ser as que os licenciandos avaliam como as principais estratégias pedagógicas para a modalidade. Uma boa aula na EJA deve privilegiar, portanto, atividades nomeadas como não tradicionais, tais como apresentação de vídeos, aulas experimentais e outras que se diferenciem da simples exposição de conhecimentos. Ainda que reconheçamos a mobilização de aulas diversificadas também como estratégias positivas para o ensino regular, os professores em formação nas salas de aula da EJA constroem um entendimento de que tais procedimentos, nomeados práticos, facilitam ao estudante jovem e adulto a "compreensão e apreensão de conceitos por muitas vezes bastante complexos para este perfil de aluno" (DPP 2/2009). 
$\mathrm{Na}$ leitura dos diários da prática pedagógica, notamos que as questões metodológicas sobre procedimentos e estratégias para a produção de melhores aulas na EJA são mais enunciadas do que propriamente os aspectos relativos, por exemplo, à seleção de conteúdos para a disciplina escolar Ciências. Assim, ainda que, ao entrar em contato com a modalidade, os professores em formação tenham estranhado o reduzido tempo para o ensino dos diversos conteúdos tradicionalmente trabalhados na disciplina escolar, as reflexões que parecem ser mais importantes no decorrer da experiência são menos quais conhecimentos são mobilizados e mais como serão trabalhados. É em meio a tal movimento que percebemos, frequentemente, a integração de conteúdos diversos em uma mesma aula. Já destacamos um exemplo no qual, em uma aula sobre as propriedades da água, também foram mobilizadas questões relativas à saúde humana (DPP 13/2015). Outro exemplo diz respeito a uma aula sobre vegetais na qual o professor regente solicitou que cada aluno levasse contribuições para a confecção de uma salada de frutas. No processo, foi possível conversar sobre conteúdos mais acadêmicos relacionados às propriedades e características botânicas de frutos e sementes e, simultaneamente, sobre reaproveitamento de cascas como adubo para a terra e replantio de sementes (DPP 19/2016). Em muitos casos, os licenciandos puderam avaliar como interessantes as atividades que foram 'desviadas', no meio do caminho, a partir de questões e debates que emergiram em sala de aula. Observe mais esse exemplo, no qual os licenciandos descrevem uma aula de Biologia Vegetal:

Fizemos uma atividade prática em que colocamos para germinar uma semente de manga e de abacate. Fizemos dois sistemas diferentes, um em terra e um hidropônico, utilizando garrafas de plásticos cortadas e as metades foram encaixadas de forma invertida, assim, a semente recebia constantemente água. Os alunos simplesmente adoraram a atividade! A turma, no geral, tem um apego grande por Biologia Vegetal. Eu particularmente adoro e percebo que eles também. Alguns trabalharam no campo e possuem conhecimentos prévios e, por isso, possuem um domínio maior nessa área. Outros, simplesmente, possuem uma horta em casa e também estão familiarizados com o plantio e cultivo de vegetais. Um amigo do [professor] fez um vídeo bem interessante mostrando a germinação da semente de abacate. Coincidiu bem com a aula, os alunos poderem ver as etapas seguintes da germinação, que é demorada e eles não conseguiriam acompanhar em sala. Ao conversar com os alunos mais sobre o abacate, que é uma das paixões do [professor] tanto pelo seu valor nutricional como também por sua história e relação com o povo Asteca, o professor percebeu que, embora eles conheçam e já tenham experimentado o abacate, os alunos ainda não haviam provado o guacamole. Após o intervalo, o [professor] retorna à sala de aula com um abacate, tomate, cebola, salsa, cebolinha e azeite. Então, como em um passe 
de mágica, prepara um guacamole delicioso. O preparo foi muito rápido, e enquanto fazia, [o professor] continuava contando a história do abacate e o seu valor nutricional. E depois de pronto, todos experimentaram com uma torradinha e até os mais desconfiados acharam gostoso (DPP 13/2015).

Todo esse movimento evidencia o quanto o binômio teoria/prática tem regulado o modo como nos constituímos professores de Ciências e Biologia tanto para o ensino regular quanto para as diversas modalidades de ensino consideradas fora da norma, o que inclui a EJA. Nos diários de prática pedagógica, percebemos sentidos de teoria e prática sendo produzidos como conceitos em oposição e, simultaneamente, complementares. É o caso de enunciados que destacam "o resultado do experimento" em aulas práticas como auxiliar "na compreensão da parte teórica" (DPP 5, 2016) dialogando com outros que, na mesma direção, afirmam que, para que os alunos tenham aulas práticas, "deveriam ter algumas aulas antes falando [sobre] alguns conceitos necessários para eles entenderem melhor os experimentos" (DPP 9, 2016). Aqui, nos chama a atenção a oposição entre teoria e prática, ainda que ambas sejam encaradas como complementares no entendimento da disciplina escolar Ciências. Vimos percebendo, no entanto, outras noções de prática significando a produção curricular na EJA, em um movimento no qual o tempo na escola e a integração dos conhecimentos constituem estranhamentos que deslocam os estudantes em formação.

Em tais deslocamentos, o termo aula prática ganha outras nuances. Uma delas diz respeito à possibilidade de trazer para a aula de Ciências elementos que modificam a sua dinâmica e a tornam diferente de outra ministrada no ensino regular. $\mathrm{O}$ trecho anteriormente destacado sobre uma aula de Biologia Vegetal nos mostra, por exemplo, que temas como germinação de sementes desembocam e convivem com questões sobre o valor nutricional de uma fruta específica (escolhida para ilustrar o evento da germinação) ea história sobre a origem asteca do nome da fruta, além de aspectos culinários e inúmeras outras possibilidades. Talvez aqui seja interessante notar que a dinâmica de uma aula de Ciências com quatro horas de duração abra espaço para que esses inúmeros aspectos passem a compor o currículo, sendo o tempo um importante elemento que participa das definições em torno da disciplina escolar na EJA.

Outra nuance que parece emergir da produção curricular na modalidade é a que entende o uso de atividades práticas como uma solução para o tempo reduzido frente ao que consideram (e aprenderam como sendo) o currículo normal nas etapas de educação básica em que se encontram. Nessa relação, a estratégia enunciada para dar conta de um conteúdo extenso em um curto tempo por exemplo, a missão de apresentar todos os invertebrados em uma única aula - é diversificar as estratégias e levar exemplos práticos para a sala de aula, utilizando imagens, coleções zoológicas, 
jogos etc. Além disso, em outros enunciados, as aulas de cunho mais prático são enunciadas como estratégia para 'devolver' a motivação dos estudantes jovens e adultos. Afinal, conforme já explicitado, o aluno da EJA vem sendo produzido como aquele estudante que, não tendo tido a oportunidade de completar a escolarização básica em época e idade que consideramos regular nas políticas de educação, frequenta a sala de aula em idade mais avançada, após um dia de trabalho e com dificuldades em compreender os conceitos estudados. Isso pode ser exemplificado no seguinte trecho:

[...] para complementar a aula [a professora] utilizou [histórias em] quadrinhos e essa simples folha deu um up em sua aula. É nítida a reação dos alunos que, quando há algo diferente na aula [...], demonstram interesse e não ficam apáticos (DPP 3/2015).

Nesse contexto, mobilizamos mais uma vez as ideias de Popkewitz (2001) ao afirmar que as explicações de sucesso e fracasso tanto dos estudantes quanto do ensino na EJA não são expressões neutras que nos auxiliam a pensar formas de ajudar os estudantes a serem bem-sucedidos. Tais explicações, diferentemente, constituem e participam de um sistema de raciocínio que produz a modalidade, seus estudantes e professores, normatizando e regulando a forma como enxergamos as possibilidades de ensinar (com seus sucessos e fracassos) esses jovens e adultos na escola.

\section{CONSIDERAÇÕES FINAIS}

Buscando concluir, nos toca pensar quais questões vêm significando essa experiência de formação docente na EJA, ou seja, de que forma enunciados que atravessam a formação desses professores de Ciências vem regulando suas ações e reflexões. É nesse movimento que produzimos conhecimentos sobre a formação de docentes de Ciências para a atuação na modalidade, analisando o modo como os discursos pedagógicos constituem uma estrutura de ideias que informa o professor em formação quem ele é ou deve ser, assim como informa quem são os alunos normais e aqueles considerados fora da norma. Queremos, portanto, no diálogo com Michel Foucault e Thomas Popkewitz, desestabilizar "as formas disponíveis de raciocínio que internalizam e fecham os espaços ocupados pelos professores [e pelos estudantes], abrindo esses espaços para outras possibilidades" (POPKEWITZ, 2001, p. 15). Afinal, ao nos referirmos aos estudantes jovens e adultos como cidadãos que necessitam de estratégias de produção de igualdade, os inscrevemos em duplos gestos - o cosmopolitismo inacabado e o estudante "deixado para trás" (POPKEWITZ, 2011) -, localizando-os em espaços intermediários entre a inclusão e a exclusão. Percebemos, nesse sentido, que qualquer estratégia pedagógica promove processos de abjeção e exclusão, uma vez que tal movimento de inclusão é também produtor de um sistema de raciocínio que normatiza e confina 
tais sujeitos em um espaço que incorpora a responsabilidade moral de redenção dos alunos por parte da ação de professores.

Parece interessante notar, no entanto, como questões sobre a experiência cotidiana desses estudantes não foram mobilizadas apenas para facilitar o aprendizado, mas para trazer elementos que transformam e, por vezes, subvertem as aulas. A noção de prática foi tomada como um interessante exemplo dessa questão, muitas vezes significando a possibilidade de trazer mais conhecimentos de Ciências para um tempo considerado curto - se pensarmos na temporalidade do curso - e, ao mesmo tempo, longo - se considerarmos a duração da aula ${ }^{3}$-, possibilitando o trabalho integrado de diversas maneiras. Nesse sentido, assumimos a experiência de formação na EJA como potencialmente subversiva. Afinal, em um jogo de estranhamentos frente a uma modalidade de educação que obriga os licenciandos a se deslocarem do que vinham compreendendo como um modelo de educação de qualidade, estes se transformam e transformam, em muitos casos, o próprio olhar para esse acontecimento que é a experiência de se tornar professor na EJA.

\footnotetext{
${ }^{3}$ Nas escolas da rede pública municipal de ensino do Rio de Janeiro, as aulas de cada área do conhecimento são realizadas em uma noite semanal com quatro horas de duração.
} 


\section{REFERÊNCIAS}

BALL, S.J.; BOWE, R. The policy processes and the processes of policy. In: BALL, S.J.; BOWE, R.; GOLD, A. (Orgs.). Reforming education and changing schools: case studies in policy sociology. Londres/Nova Iorque: Routledge, 1992. p. 6-23.

BRASIL. Ministério da Educação. Conselho Nacional de Educação. Câmara de Educação Básica. Resolução n. 1/2000. Diretrizes Nacionais Curriculares para a Educação de Jovens e Adultos. 2000a.

Ministério da Educação. Conselho Nacional de Educação. Câmara de Educação Básica. Parecer n. 11/2000. Diretrizes Nacionais Curriculares para a Educação de Jovens e Adultos. 2000b.

FERREIRA, M. S. História do Currículo e das Disciplinas: apontamentos de pesquisa. In: FAVACHO, A. M. P.; PACHECO, J. A.; SALES, S. R. Currículo, conhecimento e avaliação: divergências e tensões. Curitiba: CRV, 2013.

FOUCAULT, M. A escrita de si. In: O que é um autor? Lisboa: Passagens, 1992. p. 129-160.

. O Sujeito e o Poder. In: RABINOW, P.; DREYFUS, H. Michel Foucault: uma trajetória filosófica para além do estruturalismo e da hermenêutica. Rio de Janeiro. Forense Universitária, 1995. p. 231-249.

. Verdade e poder. Microfísica do poder. Rio de Janeiro: Paz e Terra, p.35-54 2003.

Conversa com Michel Foucault. In: Ditos e Escritos, 2010. vol. VI.

A arqueologia do saber. Rio de Janeiro: Forense Universitária, 2014a.

A ordem do discurso. São Paulo: Edições Loyola. 2014b.

HAKING, I. Kinds of People: moving targets. Proceedings of British Academy 151. The British Academy 2007. p. 285-318.

HALL, S. A centralidade da cultura: notas sobre as revoluções culturais do nosso tempo. Educação \& Realidade, v. 22, n. 2, p. 15-46, jul./dez. 1997. Disponível em:〈http://www.gpef.fe.usp.br/teses/agenda_2011_02.pdf〉.

LARROSA, J. Experiencia y alteridade em educacion. In: SKLIAR, C.; LARROSA, J. Experiencia y alteridade em educacion. Rosario: Homo Sapiens Ediciones, 2009. p. 13-44.

MARSICO, J. Formação de professores e a constituição de subjetividades: uma abordagem discursiva do currículo na Educação de Jovens e Adultos. Tese (Doutorado em Educação) - Universidade Federal do Rio de Janeiro, 2018.

POPKEWITZ, T. S. Lutando em defesa da alma: a política do ensino e a construção do professor. Porto Alegre: Artmed Editora, 2001.

Cosmopolitanism and the age of school reform: Science, Education, and Making Society by Making the Child. Routledge. 2008

El cosmopolitismo y la era de la reforma escolar. Ediciones Morata. 2009.

Cosmopolitismo, o cidadão e os processos de abjeção: os duplos gestos da pedagogia. Cadernos de Educação. Pelotas, (38): 361-391, jan./abr. 2011.

Social Epistemology, the Reason of "Reason" and the Curriculum Studies. Education Policy Analysis Archives, AAPE, v. 22, n. 22, p. 1-23. 2014. 


\section{RESUMO}

Investigamosos discursos que regulam os processos de subjetivação de professores em formação inicial para a atuação na Educação de Jovens e Adultos. Interessa-nos compreender os enunciados produzidos em diferentes contextos discursivos de produção de conhecimentos que normatizam o que podemos pensar sobre a modalidade e seus sujeitos, em processos que incluem e, simultaneamente, excluem os estudantes. Percebemos a produção de um estudante - e de um professor - fora da norma, produzindo efeitos de poder que regulam a produção das subjetividades discentes e docentes. Assim, ao nos referirmos ao estudante jovem e adulto como o cidadão que necessita de estratégias de produção de igualdade, situamos esses estudantes em espaços intermediários entre a inclusão e a exclusão.

\section{PRODUCING CURRICULA AND SCIENCE TEACHERS IN THE EJA: BETWEEN NORMALIZATIONS AND DISPLACEMENTS}

\section{ABSTRACT}

We investigate the discourses that regulate the processes of subjectivation of teachers in initial formation for the performance of Youth and Adult Education. We are interested in understanding the statements produced in different discursive contexts of knowledge production that normalize what we can think about the modality and its subjects, in processes that include and simultaneously exclude students. We perceive the production of a student - and a teacher - outside the norm, producing effects of power that regulate the production of student and teaching subjectivities. Thus, when we refer to the young and adult student as the citizen who needs strategies of production of equality, we place these students in spaces between inclusion and exclusion.

\section{CONSTRUYENDO CURRÍCULOS Y PROFESORES DE CIENCIAS EN LA EJA: ENTRE NORMALIZACIONES Y DESPLAZAMIENTOS}

\section{RESUMEN}

Investigamos los discursos que regulan los procesos de subjetivación de maestros em formación inicial para la actuación em La Educación de Jóvenes y Adultos. Nos interesa comprender los enunciados producidos en distintos contextos discursivos de producción de conocimientos que normalizan lo que podemos pensar sobre la modalidad y sus sujetos, en procesos que incluyen y, al mismo tiempo, excluyen a los estudiantes. Se percibe la producción de un estudiante - y de un maestro - fuera de la norma, produciendo efectos de poder que regulan la producción de las subjetividades discentes y docentes. Así, al referirse al estudiante joven y adulto como el ciudadano que necesita estrategias de producción a igualdad, situamos a esos estudiantes en espacios intermedios entre la inclusión y la exclusión. 